\title{
Reversal of endocrine resistance in breast cancer: interrelationships among 14-3-3 gene signature associated with mitosis
}

\author{
Anna Bergamaschi, Barbara L Christensen and Benita S Katzenellenbogen ${ }^{*}$
}

\begin{abstract}
Introduction: Despite the benefits of estrogen receptor (ER)-targeted endocrine therapies in breast cancer, many tumors develop resistance. 14-3-3 ל/YWHAZ, a member of the 14-3-3 family of conserved proteins, is over-expressed in

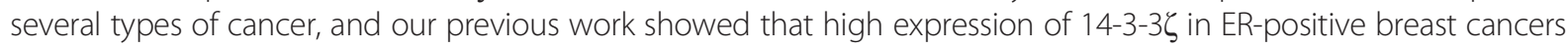
was associated with a poor clinical outcome for women on tamoxifen. Therefore, we now probe the role of $14-3-3 \zeta$ in endocrine resistance, and we examine the functional dimensions and molecular basis that underlie 14-3-3 $\zeta$ activities.

Methods: From analyses of four independent breast cancer microarray datasets from nearly 400 women, we characterized a gene signature that correlated strongly with high expression of $14-3-3 \zeta$ in breast tumors and examined its association with breast cancer molecular subtypes and clinical-pathological features. We investigated the effects of altering 14-3-3 $\zeta$ levels in ER-positive, endocrine sensitive and resistant breast cancer cells on the regulation of $14-3-3 \zeta$ signature genes, and on cellular signaling pathways and cell phenotypic properties.

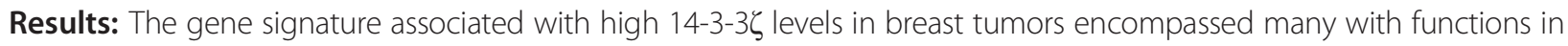
mitosis and cytokinesis, including aurora kinase-B, polo-like kinase-1, CDC25B, and BIRC5/survivin. The gene signature correlated with early recurrence and risk of metastasis, and was found predominantly in luminal B breast cancers, the more aggressive ER-positive molecular subtype. The expression of the signature genes was significantly decreased or increased upon reduction or overexpression of $14-3-3 \zeta$ in ER-positive breast cancer cells, indicating their coregulation.

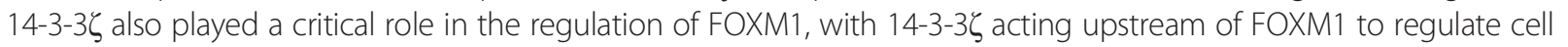
division-signature genes. Depletion of $14-3-3 \zeta$ markedly increased apoptosis, reduced proliferation and receptor tyrosine kinase (HER2 and EGFR) signaling, and, importantly, reversed endocrine resistance.

Conclusions: This study reveals that $14-3-3 \zeta$ is a key predictive marker for risk of failure on endocrine therapy and serves a pivotal role impacting growth factor signaling, and promoting cell survival and resistance to endocrine therapies. Targeting $14-3-3 \zeta$ and its coregulated proteins, such as FOXM1, should prove valuable in restoring endocrine sensitivity and reducing risk of breast cancer recurrence.
\end{abstract}

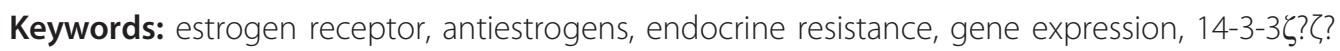

\section{Introduction}

Approximately $70 \%$ of breast cancers are positive for estrogen receptor (ER) $\alpha$ at diagnosis, and these patients often benefit from endocrine therapies that target ER, because the proliferative drive of these tumors and many of their phenotypic properties result from

\footnotetext{
* Correspondence: katzenel@illinois.edu
Department of Molecular and Integrative Physiology, University of Illinois

* Correspondence: katzenel@illinois.edu and College of Medicine at Urbana-Champaign, 524 Burrill Hall, 407 South Goodwin Avenue, Urbana, IL, 61801, USA
}

(C) 2011 Bergamaschi et al.; licensee BioMed Central Ltd. This is an open access article distributed under the terms of the Creative Commons Attribution License (http://creativecommons.org/licenses/by/2.0), which permits unrestricted use, distribution, and reproduction in any medium, provided the original work is properly cited. estrogens acting through the ER [1]. ER is a master regsurvival and proliferation-promoting factors and downregulating proapoptotic and tumor suppressing factors [1-4]. Endocrine therapies in breast cancer, when effective, are desirable because they are generally well tolerated and avoid the morbidity associated with radiation and chemotherapies.

All forms of endocrine therapies, including ER antagonists such as the selective estrogen receptor modulators 
(SERMs) tamoxifen and raloxifene, and the selective ER downregulator (SERD) fulvestrant, function by interrupting estrogen signaling through the ER. These therapies targeting the ER have profoundly impacted breast cancer treatment and improved patient survival [5]. The benefit of endocrine therapies, however, is limited by the development of resistance, a process that appears to result from upregulation of growth factor and protein kinase signaling pathways that provide an alternate mechanism in support of tumor cell proliferation and survival [6-9]. Hence, there is great interest in identifying and targeting, by inhibition or downregulation, key factors that mediate endocrine resistance.

We previously identified $14-3-3 \zeta$, also known as YWHAZ, from gene expression profiling on a cohort of ER-positive breast tumor samples and found that

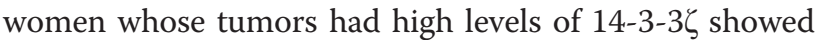
a poor clinical outcome on tamoxifen [10]. However, the molecular mechanisms underlying this poor clinical response on endocrine therapy still remain unknown. $14-3-3 \zeta$ is a member of a highly conserved family of 143-3 proteins, and it functions as a scaffold or platform that regulates the activity and stability of interacting proteins by binding to their phosphoserine and phosphothreonine motifs [11-15]. Therefore, we have undertaken studies to probe the functional dimensions of 143-3 $\zeta$ activity and its mechanistic basis in which we: characterize a gene signature associated with overexpression of $14-3-3 \zeta$ in breast tumors; determine the association of $14-3-3 \zeta$ with the molecular subtypes and clinical pathological features of breast cancers; identify the gene regulations, cellular pathways, and cell phenotypic properties modulated by $14-3-3 \zeta$ status; and examine the role of $14-3-3 \zeta$ in breast cancer endocrine resistance. Our studies reveal that $14-3-3 \zeta$ is a key survival factor integrating proliferative inputs from multiple cellular pathways, and that downregulation of $14-3-3 \zeta$ can restore endocrine sensitivity in resistant breast cancer cells. The findings suggest that targeting $14-3-3 \zeta$ or the proteins it regulates could be a useful approach for enhancing and prolonging the effectiveness of endocrine therapies.

\section{Materials and methods}

Analysis of microarray datasets and identification of a 143-3 $\zeta$ gene signature

Microarray gene expression analysis and data processing were from four independent clinical studies encompassing 390 ER-positive primary breast tumors [10,16-18]. From the Frasor et al. dataset [10], we included the 67 ER-positive tumors from patients who subsequently underwent endocrine therapy with tamoxifen and microarrays were analyzed as described therein. From the van't Veer et al. dataset, we included 47 ER-positive breast tumors and associated expression data, and clinical data were obtained from Rosetta Inpharmatics (Kirkland, WA, USA) [17]. Downloaded log base 2 data were transformed to linear values and uploaded to GeneSpring GX 7.3 (Agilent Technologies, Santa Clara, CA, USA) From the Wang et al. dataset [18], we included 209 ER-positive breast tumors, and gene expression and clinical data were obtained from GEO (Series GSE2034). The downloaded data were transformed into GeneSpring GX 7.3 and chips and genes were median normalized and median polished. Log base 2 data from 67 ER-positive primary breast tumors from the Sorlie et al. cohort [16] were downloaded from GEO (Series 4335), uploaded to GeneSpring GX 7.3 and then chips and genes were median normalized. Frasor et al. [10] and Wang et al. [18] used the Hu133A-Affymetrix microarray platform; van't Veer et al. [17] used Hu25KAgilent arrays; and Sorlie et al. [16] used cDNA Stanford arrays containing 8,102 genes. For the Sorlie et al. dataset, all the patients were treated with either doxorubicin or 5-fluorouracil and mitomycin $\mathrm{C}$ but no information on hormonal or other neo-adjuvant treatment was available. For Wang et al. and van't Veer et al., no treatments were publicly available or could be associated with any samples.

Hierarchical clustering of data was performed and displayed using Eisen Cluster and TreeView software for analysis and visualization. Based on 14-3-3 $\zeta$ microarray expression levels, breast cancer samples [10] were divided into high $(\geq 1.8 \log 2)$ and low $(<1.8 \log 2)$ 14-3$3 \zeta$ expression groups and a two-class statistical analysis of microarrays (SAM) was conducted [19]. Genes with FDR (false discovery rate) of 0.01 or less and with a fold change of three or more were included in the gene signature. The prediction analysis of microarrays method [20] was used as a cross-validation of the 14-3-3 signature.

\section{Survival analysis}

Patients were divided into high and low 14-3-3 $\zeta$ gene signature expression groups and Kaplan-Meier curves were computed by the Cox-Mantel log-rank test in WinStat for Microsoft Excel R. Fitch, Germany).

\section{Cell cultures and generation of stable cell lines}

MCF7 cells, from the American Type Culture Collection (Manassas, VA, USA), and tamoxifen-resistant MCF-7 cells [21] were grown and treated as described [2,10]. Cells

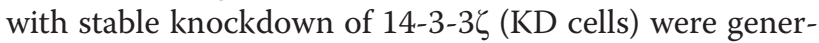
ated by transfection of pRNATin 5.1 (Ambion Austin, TX, USA) containing shRNA (TCTTGAGGTGGCCAATATTTC) targeting the 3' UTR. Cells were selected in the presence of hygromycin B $(100 \mu \mathrm{g} / \mathrm{ml})$. Some transfections utilized an adenovirus-mediated method [22]. 


\section{Western blot analysis}

Whole-cell extracts were prepared using 1X RIPA Lysis buffer (Upstate/Chemicon Billerica, MA, USA) supplemented with $1 \mathrm{X}$ complete protease inhibitor (Roche, Basel, Switzerland). Western blotting used antibodies

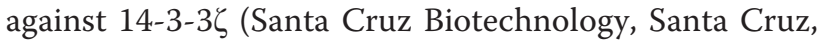
CA, USA), $\beta$-actin (Sigma-Aldrich, St Louis, MO, USA), phosphoepidermal growth factor receptor (EGFR), phospho- human epidermal growth factor receptor 2 (HER2), phospho- mitogen activated protein kinase (MAPK) and phospho-AKT/PKB (protein Kinase B) (Cell Signaling, Danvers, MA, USA).

\section{RT-PCR and quantitative PCR}

Total RNA was isolated from cells using TRIzol, reverse transcribed by SuperScript II reverse transcriptase (Invitrogen, Carlsbad, CA, USA), and real-time PCR performed on the ABI Prism 7900HT using SYBR Green PCR Master Mix (Applied Biosystems, Carlsbad, CA, USA) $[10,23]$.

\section{Cell proliferation, colony formation and apoptosis assays}

The WST-1 assay was used to quantify cell viability (Roche, Basel, Switzerland) and absorbance was measured at $450 \mathrm{~nm}$ using a BioRad 680 Microplate Reader (BioRad, Hercules, CA, USA). All assays were performed in triplicate. For the colony formation assay, a $1.5 \mathrm{~mL}$ base layer of agar (0.5\% agar in phenol red-free DMEM with $5 \%$ charcoal stripped-fetal calf serum) was allowed to solidify in a six-well flat-bottomed plate before the addition of $1.5 \mathrm{~mL}$ of cell suspensions containing 4,000 cells in $0.35 \%$ agar in phenol red-free DMEM with $5 \%$ charcoal stripped-FCS. The cell-containing layer was then solidified at $4^{\circ} \mathrm{C}$ for 20 minutes. Colonies were allowed to grow for 15 days at $37^{\circ} \mathrm{C}$ with $5 \% \mathrm{CO} 2$ before imaging and counting. Apoptosis was monitored based on DNA content by flow cytometry using BD-FACS Canto. Cells were fixed in $70 \%$ ethanol, stained for 30 minutes with $20 \mathrm{ug} / \mathrm{ml}$ propidium iodide (PI, Molecular Probe, Carlsbad, CA, USA) in Triton-X (Sigma, St Louis, MO, USA) in presence of DNAse-free RNAse A, and PI staining was measured [24].

\section{Results}

A gene signature and molecular phenotype in primary breast tumors associated with overexpression of 14-3-3

We previously reported that trans-hydroxytamoxifen specifically regulated the expression of a set of approximately 70 genes in ER-positive breast cancer cells. Of these, high 14-3-3 $\zeta$ was associated with a poor clinical outcome for women on tamoxifen therapy [10]. To elucidate the role that $14-3-3 \zeta$ plays in engendering this poor clinical outcome, we sought to identify genes significantly associated with high level expression of 14-3-
$3 \zeta$ and to relate these to breast cancer phenotype and gain mechanistic insights into the functions of $14-3-3 \zeta$. For this, we classified samples from our previously described cohort of 67 ER-positive primary breast tumors from women treated with tamoxifen [10] into two groups based on high or low 14-3-3 5 expression and employed two-class SAM analysis and retrieved 29 genes with an FDR of 0.01 or less and a fold change of three or more (Table 1). Using the DAVID database [25] to classify our signature gene list based on Gene Ontology terms, we found that $46 \%$ of the genes in this signature were significantly enriched in the "cell cycle"

Table 1 List of genes in the 14-3-3 $\zeta$ gene signature, based on SAM analysis

\begin{tabular}{|c|c|c|}
\hline Symbol & Name & UGRepAccession \\
\hline AURKB & Aurora kinase B & CD049340 \\
\hline BIRC5 & Effector cell peptidase receptor 1 & NM_001012271 \\
\hline BUB1 & $\begin{array}{l}\text { BUB1 budding uninhibited by } \\
\text { benzimidazoles } 1 \text { homolog }\end{array}$ & AF053305 \\
\hline CDC20 & Cell division cycle 20 homolog & BG256659 \\
\hline CDC25B & Cell division cycle 25 homolog B & NM_021873 \\
\hline CDCA8 & Cell division cycle associated 8 & BC000703 \\
\hline CENPA & Centromere protein A & BM911202 \\
\hline CEP55 & Centrosomal protein 55kDa & NM_018131 \\
\hline CKS2 & $\begin{array}{l}\text { CDC28 protein kinase regulatory } \\
\text { subunit } 2\end{array}$ & BQ898943 \\
\hline CYC1 & Cytochrome c-1 & BF569085 \\
\hline DGAT1 & $\begin{array}{l}\text { Diacylglycerol O-acyltransferase } \\
\text { homolog } 1\end{array}$ & XM_001719374 \\
\hline EXOSC4 & Exosome component 4 & BM911415 \\
\hline FAM82B & $\begin{array}{l}\text { Family with sequence similarity } 82 \text {, } \\
\text { member B }\end{array}$ & NM_016033 \\
\hline GPR172A & G protein-coupled receptor 172A & CR625605 \\
\hline HMMR & $\begin{array}{l}\text { Hyaluronan-mediated motility receptor } \\
\text { (RHAMM) }\end{array}$ & AF032862 \\
\hline HSPB8 & Heat shock 22kDa protein 8 & NM_014365 \\
\hline KPNA2 & $\begin{array}{l}\text { Karyopherin alpha } 2 \text { (RAG cohort 1, } \\
\text { importin alpha 1) }\end{array}$ & BC067848 \\
\hline NDRG1 & N-myc downstream regulated gene 1 & NM_006096.3 \\
\hline PCSK1N & $\begin{array}{l}\text { Proprotein convertase subtilisin/kexin } \\
\text { type } 1 \text { inhibitor }\end{array}$ & BM805628 \\
\hline PLK1 & Polo-like kinase 1 & AB209179 \\
\hline RECQL4 & RecQ protein-like 4 & BC020496 \\
\hline SLC16A3 & $\begin{array}{l}\text { Solute carrier family 16, member } 3 \\
\text { (monocarboxylic acid transporter } 4 \text { ) }\end{array}$ & NM_001042422 \\
\hline SLC39A4 & $\begin{array}{l}\text { Solute carrier family } 39 \text { (zinc transporter), } \\
\text { member } 4\end{array}$ & AK056900 \\
\hline SQLE & Squalene epoxidase & NM_003129 \\
\hline $\mathrm{TPX} 2$ & TPX2, microtubule-associated, homolog & NM_012112 \\
\hline TRIP13 & Thyroid hormone receptor interactor 13 & NM_004237 \\
\hline UBE2C & Ubiquitin-conjugating enzyme E2C & BC032677 \\
\hline UBE2S & Ubiquitin-conjugating enzyme E2S & BM479313 \\
\hline YWHAZ & $\begin{array}{l}\text { Tyrosine 3-monooxygenase/tryptophan } \\
\text { 5-monooxygenase activation protein, } \\
\text { zeta polypeptide }\end{array}$ & BC051814 \\
\hline
\end{tabular}


category $(P \leq 0.0001)$. Among these were BUB1 (budding uninhibited by benzimidazoles 1 homolog), BIRC5/ Survivin, CDCA8 (cell division cycle-associated protein 8), AURKB (aurora kinase B), CDC25B (cell division cycle 25 homolog B), and PLK1 (polo-like kinase 1), genes involved in mitosis and cytokinesis that tightly clustered with 14-3-3 $\zeta$ (Figure 1a).

To analyze further how these genes might help explain the molecular phenotype of tumors overexpressing 14-3$3 \zeta$, we performed unsupervised hierarchical clustering analysis and identified two main groups of patients based on 14-3-3 $\zeta$ signature gene expression. When Kaplan-Meier analysis was performed using relapse as an endpoint, patients with breast tumors having high expression of these genes (High Signature Expression) showed a significantly poorer outcome (Figure 1b).

To further assess the relevance and applicability of this 14-3-3 $\zeta$ signature, we selected ER-positive tumors from three other independent breast tumor microarray datasets with clinical information available. For all these three datasets no information on hormonal treatment
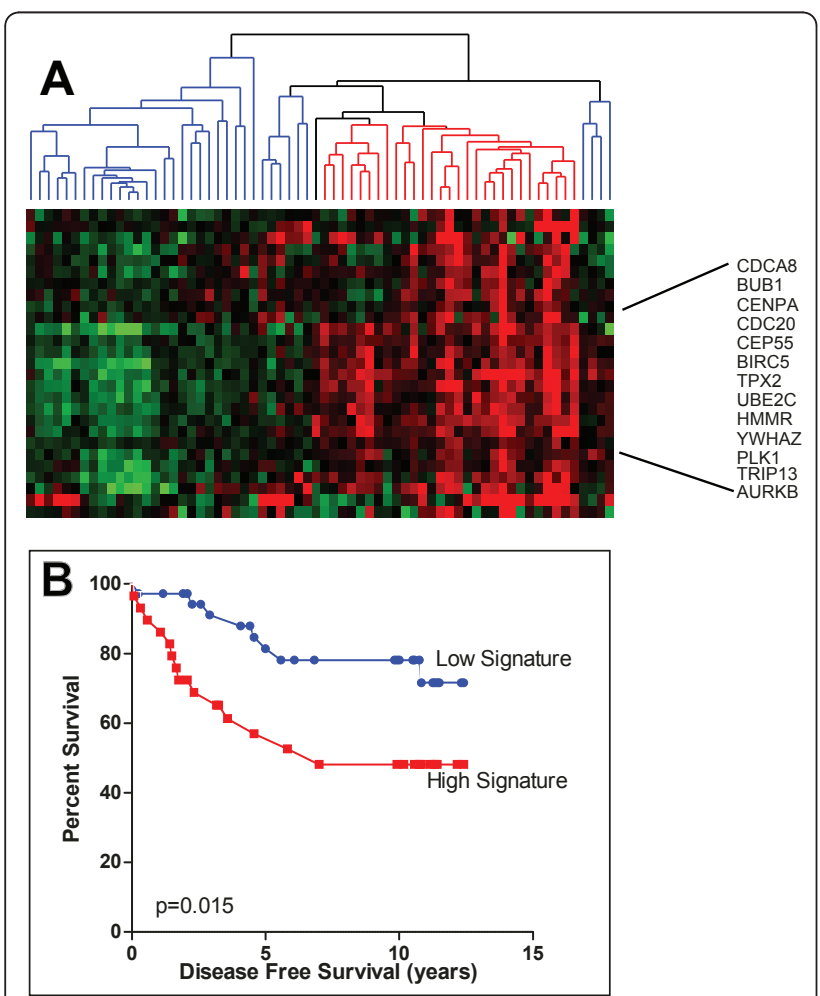

Figure 1 Identification of a 14-3-3 $\zeta$ gene signature. (a) 29 genes associated with high levels of $14-3-3 \zeta$ were identified and clustered based on their expression profile. Hierarchical clustering identified a subgroup of patients (red) characterized by elevated levels of mitosis and cytokinesis related genes. (b) Kaplan-Meier curves for the red and blue clusters of the hierarchical diagram in panel (a) distinguished between good (blue, signature low expression) and poor prognosis (red, signature high expression) patients $(P=0.015)$. was reported. Figure 2a shows the heat maps and dendrograms for expression of the 14-3-3 $\zeta$ signature genes from these three studies (panel I Wang et al., panel II van't Veer et al., panel III Sorlie et al.). The red grouping in the dendrogram represents breast tumors with high expression of the signature genes. The Wang et al. dataset [26] includes data from 209 patients, and used the same Hu133A-Affymetrix microarray platform used by Frasor et al. [10]. All 29 genes from the 14-3-3ל signature were retrieved and used for data mining. Unsupervised clustering analysis identified the red group (Signature High, $P=0.001$ Kaplan-Meier, Figure 2b) Panel I as a poor prognosis group driven by high expression of the signature genes.

In a similar fashion, we analyzed the ER-positive breast tumors $(n=49)$ included in the van't Veer dataset [17]. Given the different microarray platform used (Hu25K-Agilent), a reduced number of genes were retrieved, 17 out of the 29 genes in the $14-3-3 \zeta$ gene signature. The signature genes not retrieved by our analysis were not present on those arrays. However, the subset of patients characterized by high expression of the 14-3$3 \zeta$ signature showed a significantly earlier relapse (Figure $2 \mathrm{~b}$, Panel II). We also examined the dataset of Sorlie et al. [16,27], which used cDNA Stanford arrays containing 8,102 genes. Expression data for 19 genes of the gene signature were recovered and used for the analysis. (The signature genes not recovered were not present on these arrays.) The findings confirmed once again that overexpression of the 14-3-3 $\zeta$ signature was significantly associated with a poorer disease-free survival (Figure $2 b$, Panel III).

\section{Breast cancer subtypes and the 14-3-3 $\zeta$ gene signature}

We next examined the distribution of the five major breast cancer molecular subtypes in the set of patients that showed high expression of the $14-3-3 \zeta$ gene signature and a poor clinical outcome in the different clinical studies by using a centroid-mediated clustering algorithm. All datasets showed enrichment for luminal-B subtypes in tumors with elevated expression of the 14$3-3 \zeta$ signature genes, ranging from 53 to $58 \%$ of all tumors (Figure 2c). In addition, 7 to $21 \%$ of total ERpositive breast cancers showing high expression of the 14-3-35 gene signature were represented by the basal breast cancer subtype. For comparison we also classified tumors characterized by low expression of the 14-3-3 $\zeta$ gene signature, and found that luminal A was the most abundantly represented molecular subtype in the different datasets (data not shown). When correlated with clinical-pathological features, high level expression of the 14-3-3 $\zeta$ gene signature was significantly associated with tumor grade, with the luminal-B vs. luminal-A breast cancer subtype, and with metastasis (Figure $2 \mathrm{~d}$ ). 


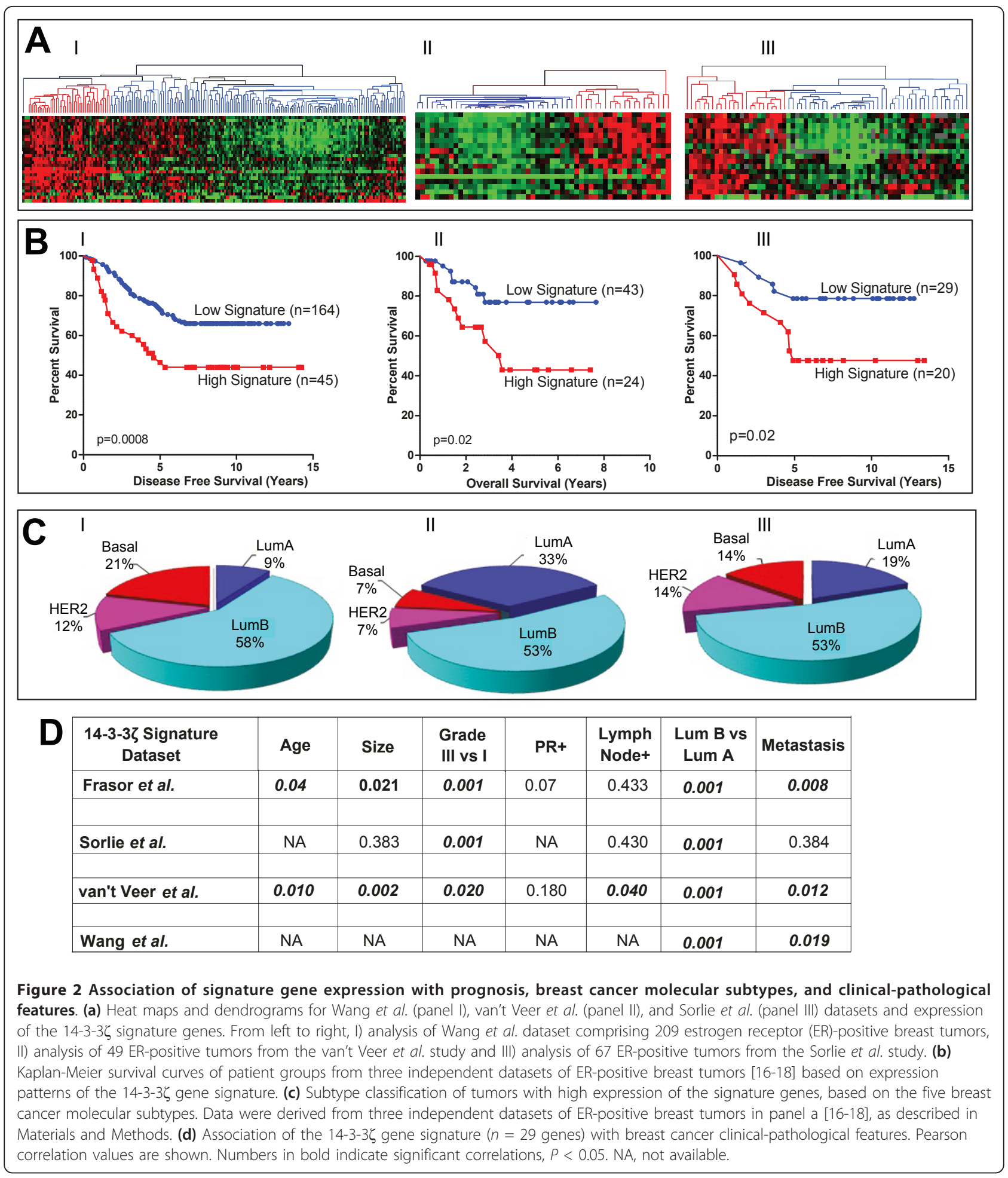

Tamoxifen selectively upregulates the zeta isoform of 143-3 proteins in breast cancer cells

Based on the findings of a clinical breast cancer gene expression signature associated with high 14-3-3 $\zeta$ and with risk of recurrence, we undertook studies to examine the effect of perturbing 14-3-3 $\zeta$ levels on gene regulations and phenotypic properties of ER-positive breast cancer cells. Because 14-3-3 $\zeta$ belongs to a family of highly conserved proteins, we first examined whether tamoxifen affected regulation of the various members of 
the 14-3-3 family. Of note, the mRNA level of only the zeta isoform was markedly upregulated by tamoxifen (Figure 3a, $P=0.0004$ ), with $14-3-3 \zeta$ reaching the maximal mRNA level by 24 hours (Figure $3 \mathrm{~b}$ ) and maximal protein level at 48 to 72 hours after tamoxifen (Figure $3 a)$. Of the other 14-3-3 isoforms, only 14-3-3 $\beta$ showed low but significant $(P=0.036)$ upregulation by tamoxifen. Cotreatment with tamoxifen and the ER antagonist ligand and ER downregulator, ICI 182,780 (ICI), reversed the stimulatory effect of tamoxifen (Figure $3 \mathrm{~b}$ ), indicating the requirement for ER in the upregulation of $14-3-3 \zeta$.

Functional characterization of the effect of 14-3-3 knockdown on the phenotypic properties of ER-positive breast cancer cells

To probe the functional roles of $14-3-3 \zeta$ in breast cancer aggressiveness and in antiestrogen resistance, we examined the effect of long-term reduction of 14-3-3 $\zeta$

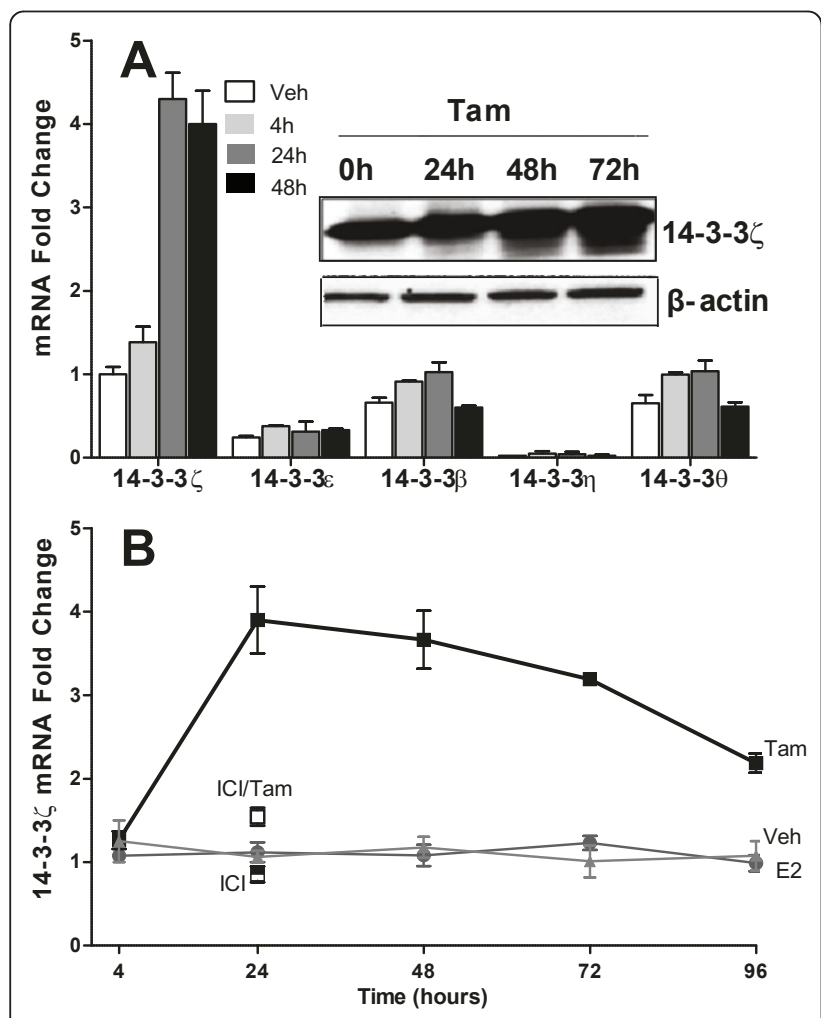

Figure 3 Regulation of 14-3-3 family members in MCF-7 breast cancer cells upon ligand treatment. (a) Expression of 14-3-3 isoforms at the indicated times $(0,4,24,48$ hours) after $1 \mu \mathrm{M}$ tamoxifen (Tam) treatment. $14-3-3 \sigma$ is expressed at a very low level and is therefore not shown. Inset shows 14-3-35 protein evaluated by western blot after Tam treatment for 0 to 72 hours with $\beta$-actin as the loading control. (b) Cells were cultured in the presence of vehicle (0.1\% ethanol), 1 MM Tam, 10 nM E2, 1 MM ICl 182,780 (ICI) alone or $\mathrm{ICl}$ in combination with $10 \mathrm{nM}$ Tam for various times. RNAs were measured by real-time PCR.. on cell phenotypic properties by stable expression of interfering short hairpin shRNA in ER-positive MCF7 cells. We subcloned the human U6 promoter [28] into the plasmid vector pRNAtin and five shRNAs targeting the 3'-noncoding region of $14-3-3 \zeta$ and a non-targeting control shRNA were designed. Several clones showed 14-3-3 $\zeta$ reduction, but only two showed a good level of reduction of $14-3-3 \zeta$ (reduction by approximately $60 \%$ or $70 \%$ ). We assume this likely reflects our findings, presented in more detail below, that depletion of $14-3-3 \zeta$ greatly slows cell growth and induces apoptosis. Hence, cells are unable to survive in the complete absence of this protein.

We undertook characterization of the two clones showing a downregulation by about 60 to $70 \%$, and found similar trends, so we present data only for the clone showing the greatest $14-3-3 \zeta$ depletion (Figure 4a). These cells, referred to as $14-3-3 \zeta \mathrm{KD}$, showed $35 \%$ and $30 \%$ of the parental cell content of $14-3-3 \zeta$ at the RNA and protein level, respectively (Figure 4a). This knockdown of 14-3-3 $\zeta$ did not affect the levels of other 14-3-3 isoforms (data not shown). To validate the specificity of our shRNA knockdown, which was targeted to

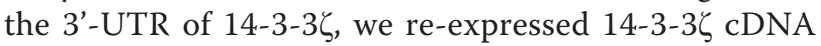
that did not contain the 3'-UTR (denoted KD_R, knockdown and re-expression). Re-expression of $14-3-3 \zeta$ in the KD cells substantially restored $14-3-3 \zeta$ mRNA and protein (KD_R, Figure 4a).

Cells with downregulation of $14-3-3 \zeta$ showed enhanced sensitivity to tamoxifen inhibition of cell viability (Figure

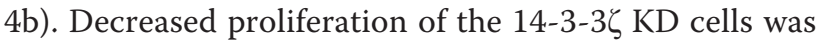
explained by a marked increase of cells in the sub-G1 phase of the cell cycle and a decrease of cells in G1 and G2/M phases (Figure 4c), based on flow cytometric analysis. Moreover, apoptosis was found to be greatly increased with time of tamoxifen treatment in 14-3-3 depleted cells compared with control cells (Figure 4d).

\section{4-3-3 knockdown impacts FOXM1 and 14-3-3 $\zeta$ signature genes}

Next, we selected several genes from the 14-3-3ל signature and monitored their levels in cells with stable 14-3$3 \zeta$ knockdown. Of note, reduction of $14-3-3 \zeta$ was associated with a significant reduction in the expression of signature genes, including BIRC5/Survivin, CDCA8, AURKB, PLK1, BUB1, and CDC25B, and this was reversed by restoration of $14-3-3 \zeta$ (Figure 5a). Further, we inspected the cellular level of FOXM1, a transcription factor known to regulate expression of cell cycle genes [29,30], including some of our signature genes. In 14-3-3 $\zeta$ KD cells, we observed a significant decrease in FOXM1 mRNA and a particularly marked reduction of FOXM1 protein correlating with low levels of 14-3-3 (Figure $5 \mathrm{a}$ and $5 \mathrm{~b}$ ). Further, re-expression of $14-3-3 \zeta$ 


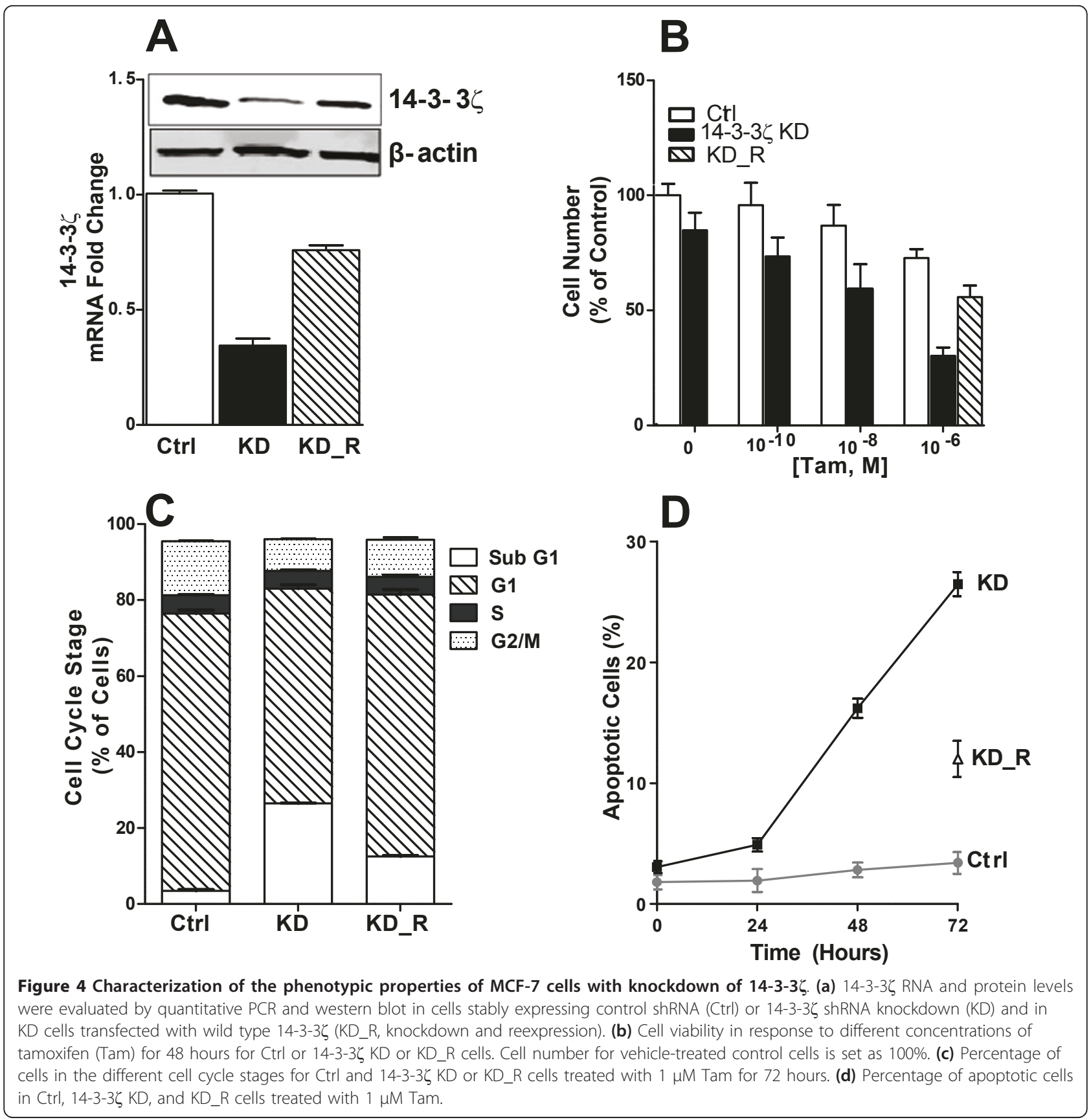

(KD_R cells) substantially restored the level of FOXM1 (Figure $5 \mathrm{a}$ and $5 \mathrm{~b}$ ).

By transient knockdown of FOXM1 with siRNA (to 10\% of control level, Figure 5c), we observed a marked reduction of AURKB, BIRC5, CDCA8, and CDC25B but little impact on $14-3-3 \zeta$ (Figure $5 \mathrm{c}$ ), indicating that the major regulatory effect of FOXM1 on these genes is downstream of 14-3-3 . To explore this further, we treated cells with FOXM1-expressing adenovirus and found that elevation of FOXM1 had no effect on 14-3-3 $\zeta$ levels in either control or $14-3-3 \zeta \mathrm{KD}$ cells (Figure $5 \mathrm{~d}$ ), whereas the overexpression of FOXM1 increased expression of the four signature genes and fully abrogated the effect of 14-3$3 \zeta$ knockdown (Figure 5d). This pattern of regulation provides support for the regulatory effect of FOXM1 on these

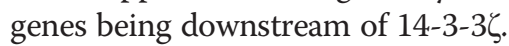

\section{Downregulation of $14-3-3 \zeta$ in tamoxifen-resistant cells} restores sensitivity to the inhibitory effects of antiestrogens

To assess the role of $14-3-3 \zeta$ in antiestrogen resistance, we used a tamoxifen-resistant breast cancer cell line 


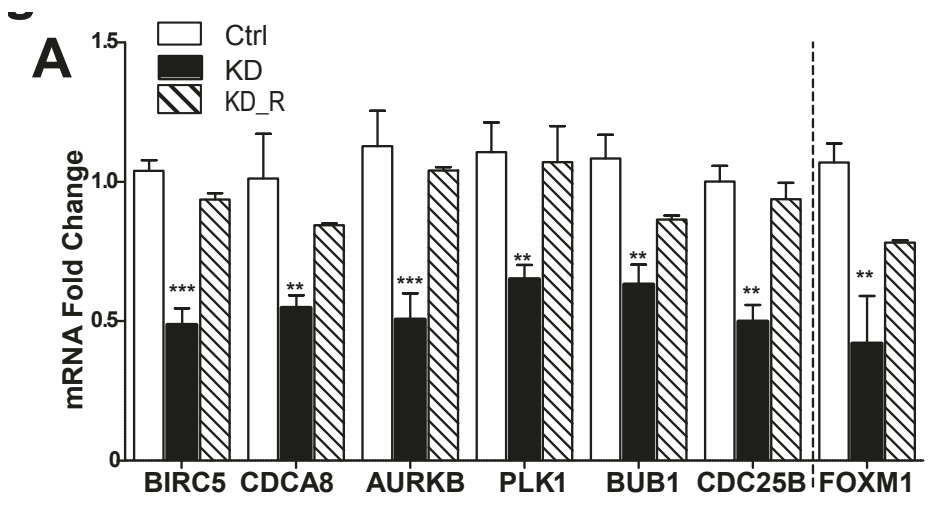

B
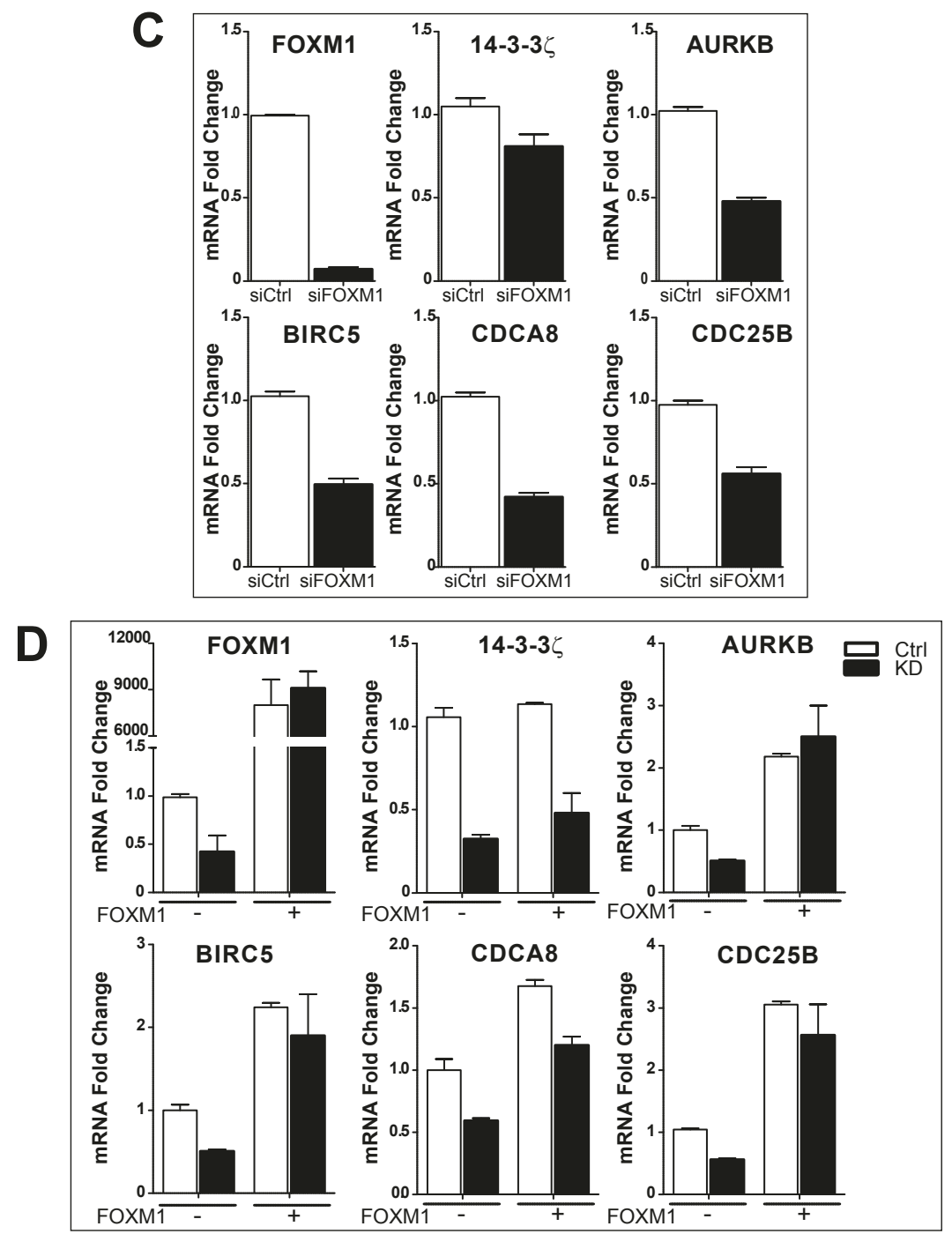

Figure 5 Expression of $14-3-3 \zeta$ and associated signature genes in 14-3-3 $\zeta$ knockdown MCF-7 cells. (a) Real-time PCR for six signature

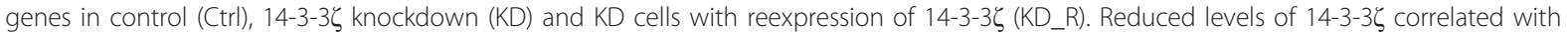

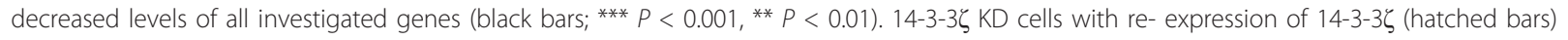

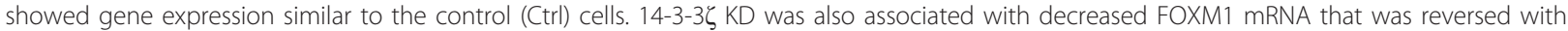

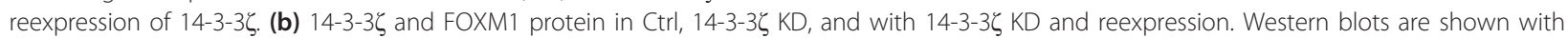

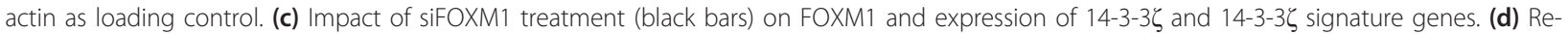

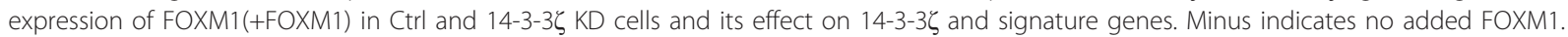


$\left(\mathrm{Tam}^{\mathrm{R}}\right.$ cells) generated in our laboratory [21]. 14-3-3ל was three times higher in these resistant cells than in the parental MCF7 cells (data not shown), and tamoxifen elicited growth stimulation, rather than growth inhibition, in these cells (Figures $6 \mathrm{a}$ and $6 \mathrm{~b}$ ). Knockdown of $14-3-3 \zeta$ eliminated tamoxifen stimulation of proliferation and also reduced control cell proliferation (Figure 6b). 14-3-3 $\zeta$ knockdown also greatly reduced anchorage-independent growth of antiestrogen-resistant cells which grew well in the presence of tamoxifen and raloxifene without 14-3-3 3 knockdown (Figure 6c).
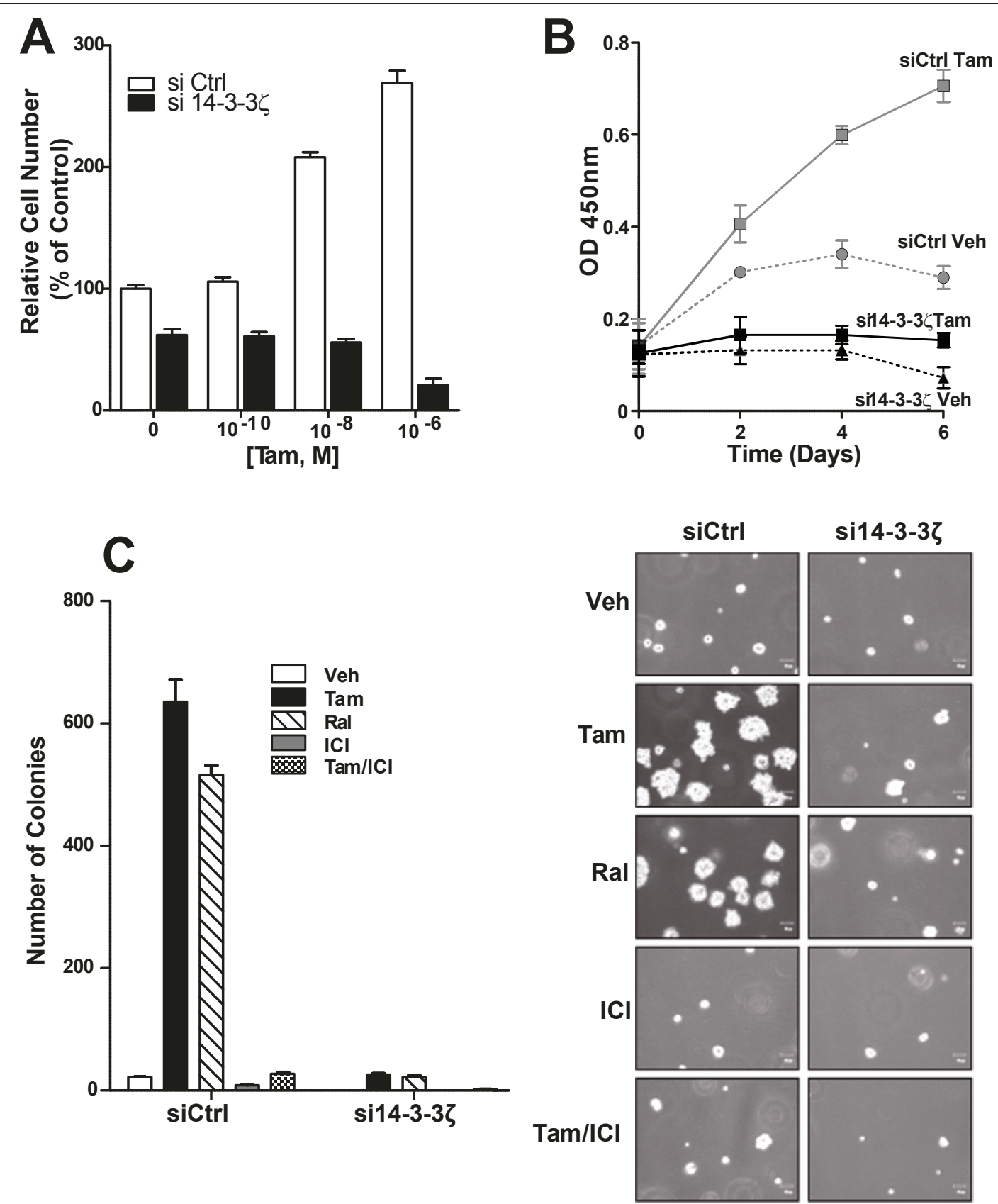

Figure 6 Effects of $\mathbf{1 4 - 3 - 3 \zeta}$ on viability and colony formation of tamoxifen-resistant (Tam ${ }^{\mathrm{R}}$ ) MCF-7 cells. (a) Sensitivity to tamoxifen measured as a function of cell viability in response to increasing concentrations of ligand for 96 hours. Vehicle-treated control cells were set at 100\%. (b) Cell viability monitored over time in Tam ${ }^{R}$ cells with siCtrl or si14-3-3 and treatment with tamoxifen (Tam) for the days indicated. (c) Colony formation of $\operatorname{Tam}^{\mathrm{R}} \mathrm{Ctrl}$ siRNA or $14-3-3 \zeta$ siRNA cells in soft agar after 15 days in the presence of vehicle, Tam $(1 \mu \mathrm{M})$, raloxifene $(1 \mu \mathrm{M})$, fulvestrant (ICI 182,780) (1 HM) and Tam plus ICI (10 nM and 1 MM). Colonies were stained, counted, and photographed. 


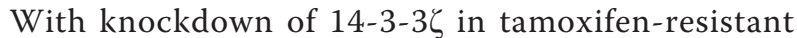
cells, we observed a downregulation of the 14-3-3 $\zeta$ signature genes and a marked reduction in FOXM1 (Figure 7a, black bars), and also a suppression of control (veh) cell proliferation and a greatly reduced stimulation of proliferation by tamoxifen (Figure 7b). With FOXM1 overexpression (Figure 7a, hatched bars), expression of 14-3-3 $\zeta$ signature genes was increased (Figure 7a), and this FOXM1 elevation resulted in an increase in control cell proliferation with only a limited further stimulation by tamoxifen (Figure 7b). When 14-3-3 $\zeta$ was depleted from cells and FOXM1 was overexpressed, expression of the signature genes was restored to or even increased above the control level (Figure 7a, grey bars), and basal proliferation and stimulation of proliferation by tamoxifen were restored (Figure 7b).

\section{Effect of 14-3-3 $\zeta$ overexpression or knockdown on markers of hormone resistance}

As it is known that enhanced activation of growth factor receptors and downstream kinases can underlie tamoxifen resistance, we examined the impact of $14-3-3 \zeta$ status on possible changes in these signaling proteins. We modulated the levels of $14-3-3 \zeta$ by adenovirus overexpression or knockdown by RNA interference in tamoxifen-resistant cells, and we monitored over time the status of phosphorylated HER2, EGFR, and downstream signaling kinases AKT and MAPK in cells treated with tamoxifen. Of note, with elevated levels of $14-3-3 \zeta$, the tamoxifen-resistant cells showed enhanced phosphorylation of HER2, EGFR, and MAPK, with lesser impact on pAKT (Figure 8, right). The opposite effects were observed when cells were depleted of $14-3-3 \zeta$, namely suppression of activation of HER2, EGFR, AKT, and MAPK (Figure 8, middle). Hence, 14-3-3 $\zeta$ plays an important role in modulating the activation status of these key receptors and protein kinases.

\section{Discussion}

Endocrine therapies initially provide benefit in many of the approximately $70 \%$ of breast cancers that are ERpositive, but the effectiveness of endocrine therapies is often lost with time because resistance to treatment develops. In this study, we show that $14-3-3 \zeta$ is a critical factor promoting endocrine resistance. It is upregulated in endocrine-resistant breast cancer and its depletion reverses resistance and restores sensitivity to endocrine treatments.

In probing the functional dimensions of the roles 14$3-3 \zeta$ plays in endocrine resistance, we have identified a gene signature associated with high expression of 14-3$3 \zeta$, based on microarray datasets from approximately 400 women with ER-positive breast tumors, and we find that this gene signature is correlated with higher tumor grade, increased metastasis, and risk of early recurrence. Up or downregulating the level of 14-3-3 $\zeta$ greatly impacted the phenotypic properties of breast cancer cells, including their proliferation, apoptosis, and

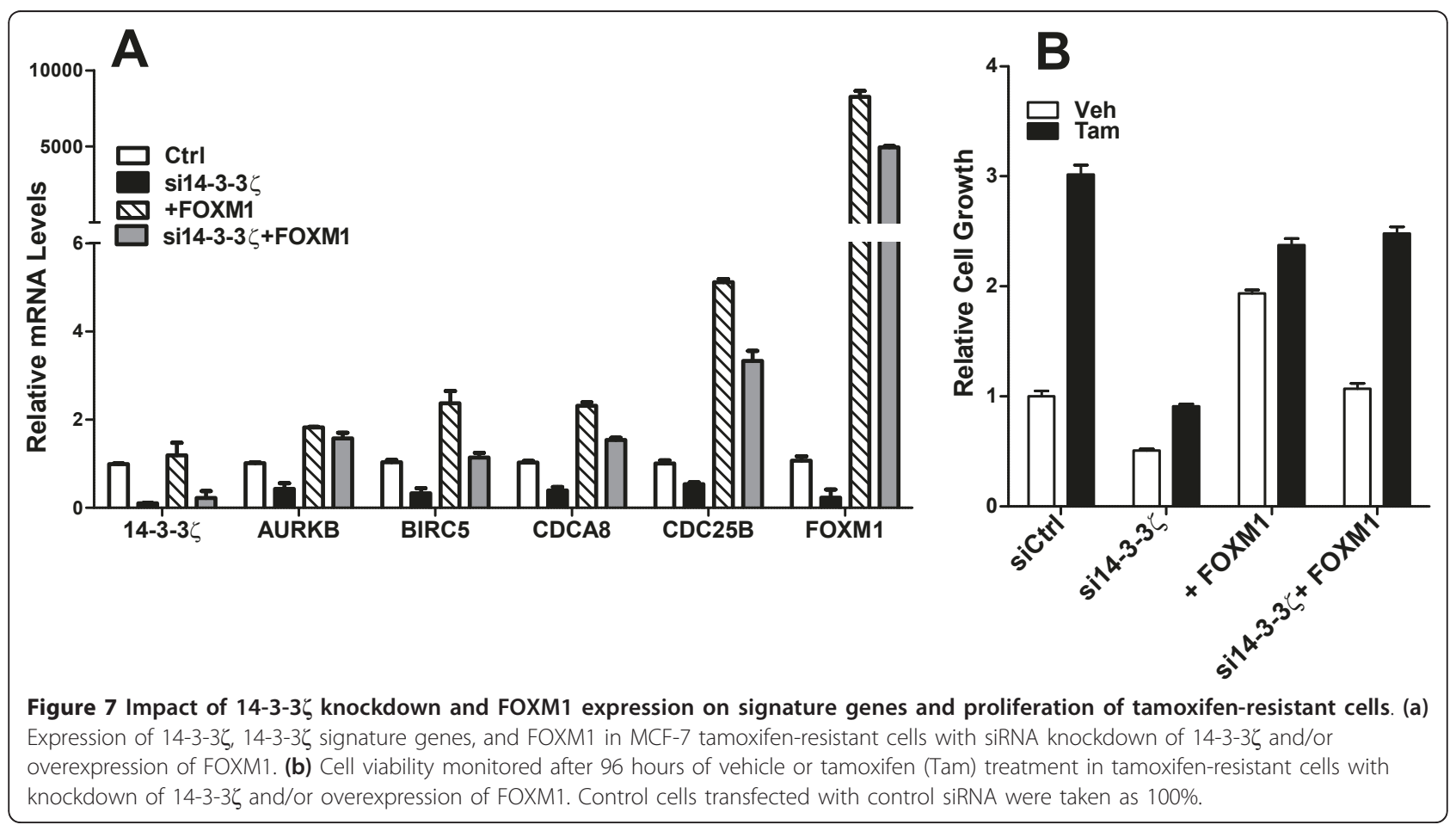




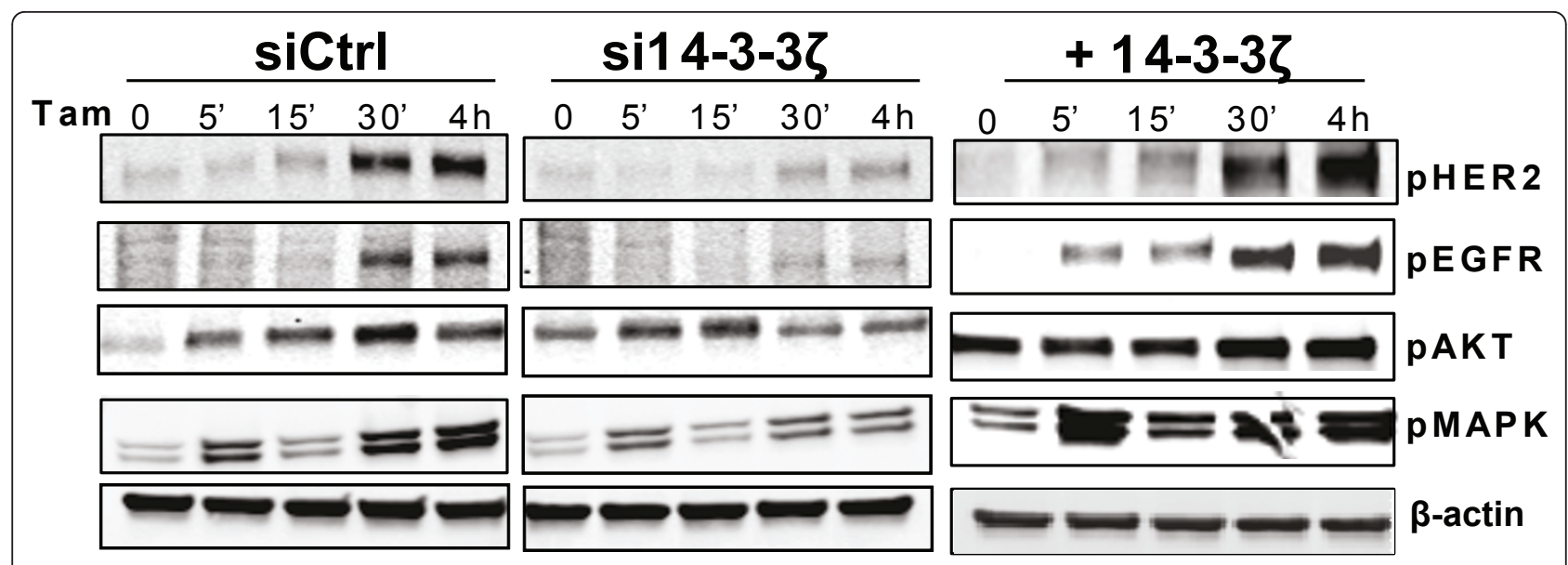

Figure 8 14-3-3 $\zeta$ status impacts the activation of key signaling proteins. Phosphorylation of human epidermal growth factor receptor 2 (HER2), epidermal growth factor receptor (EGFR), AKT/Protein kinase B (AKT/PKB), and mitogen activated protein kinase (MAPK) was investigated by western blot in tamoxifen-resistant cells following siRNA knockdown or overexpression of $14-3-3 \zeta$ and treatment with $1 \mu \mathrm{M}$ tamoxifen (Tam).

endocrine sensitivity. Notably, downregulation of 14-3$3 \zeta$ restored sensitivity to endocrine treatments in endocrine-resistant breast cancer cells and reduced the expression of signature genes associated with proliferation and survival, effects that were reversed by reexpression of $14-3-3 \zeta$. Thus, $14-3-3 \zeta$ appears to function as a key therapeutic target whose downregulation could improve response to endocrine therapies.

\section{A gene signature and breast cancer molecular subtypes associated with 14-3-3 $\zeta$ overexpression and poor patient outcome}

Using a training set of 67 adjuvant tamoxifen-treated ER-positive breast tumors, we identified, by a supervised analysis, a set of 29 genes that strongly correlated with expression of 14-3-3 . By taking advantage of several publicly available large independent breast cancer datasets, we confirmed the ability of the $14-3-3 \zeta$ signature to predict clinical outcome. These four large datasets represent a combined total of nearly 400 breast cancer patients with ER-positive tumors. The gene signature was robustly represented by cell cycle-related genes, and factors such as BIRC5/survivin, that have been shown to play important roles in mitosis and to promote cell survival $[26,29,31,32]$.

Our studies are the first to reveal the detrimental role of $14-3-3 \zeta$ in endocrine therapy resistance, and they provide a molecular basis for our observation of a poor clinical outcome for women with breast cancers having

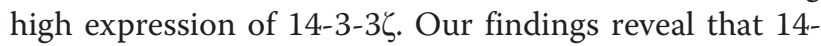
$3-3 \zeta$ is associated with a gene signature rich in genes that encode proteins with central roles in mitosis and the segregation of chromosomes during cell division. The enzyme aurora B kinase, which is part of the chromosome passenger complex, and the protein kinase
BUB1 have through recent studies been documented as essential for accurate chromosome inheritance at mitosis. Aurora B kinase appears to act as a fidelity checkpoint factor for mitosis by reversibly phosphorylating target proteins at the centromere and kinetochore [33-35]. BUB1 phosphorylation of a specific threonine in histone $\mathrm{H} 2 \mathrm{~A}$ has been implicated in the recruitment of the chromosome passenger complex to centromeres [35]. Survivin, also part of our gene signature, binds to aurora B in the chromosome passenger complex, contributing to events that control the normal segregation of chromosomes during cell division. Alterations in the production of these factors, which we observed as a consequence of upregulation of $14-3-3 \zeta$ by tamoxifen and associated with the development of endocrine resistance, might thereby also impair proper chromosome segregation and affect cell viability and tumor progression. Indeed, we found that changes in the levels of 14$3-3 \zeta$ by knockdown or overexpression had marked effects on cell viability, apoptosis, and on the cell cycle in MCF-7 tamoxifen-resistant cells, and also in ER-positive and HER2-positive BT474 cells based on preliminary studies.

Our studies also uncovered a previously unknown

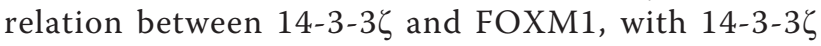
playing a crucial role in regulating FOXM1. This was observed in MCF-7 parental and tamoxifen-resistant cells, as shown in this study, and also in ER-positive HER2-positive BT474 breast cancer cells (data not shown). Thus, knockdown of 14-3-3 $\zeta$ brought about an almost complete loss of cellular FOXM1 protein, which

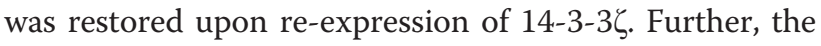

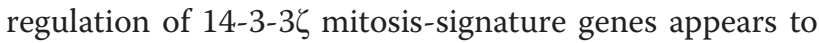

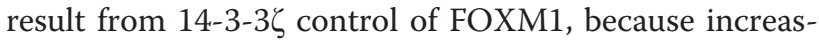
ing FOXM1 levels in the context of 14-3-3 $\zeta$ knockdown 
effected a parallel restoration of the expression of these genes. Thus, 14-3-3 $\zeta$ appears to function upstream of FOXM1 in regulating these signature genes. Some of the effects of $14-3-3 \zeta$ status on the cell cycle might reflect changes in the cellular level of FoxM1, which is known to regulate genes involved in G2/M, some of which were investigated in this study including BIRC5, AURKB, CDCA8, CDC25B, and PLK1 [29,30].

The majority of ER-positive breast tumors overexpressing 14-3-3 $\zeta$ were of the luminal B subtype, tumors with a poorer outcome compared with luminal A. Consistent with this, comparative genomic hybridization analyses have indicated that one of the most recurrent alterations in luminal B tumors is gain/amplification of the $8 \mathrm{q}$ region that harbors $14-3-3 \zeta(8 q 22)$ [36]. In addition to the prominent association of 14-3-3 $\zeta$ with ER-positive luminal B tumors, ca. 12\% were basal breast cancers, another subtype with a poor prognosis. Collectively, our observations in primary breast tumors and in breast cancer cells in vitro provide evidence that the overexpression of $14-3-3 \zeta$ and the associated $14-3-3 \zeta$ gene signature identify a subgroup of ER-positive tumors most likely to be resistant to endocrine therapies and to show early recurrence. In addition, our studies reveal that 143-3 $\zeta$ expression can also be increased as a consequence of tamoxifen treatment, and therefore, ironically, that tamoxifen itself, through upregulation of $14-3-3 \zeta$, may be contributing to the development of endocrine resistance.

\section{Broad impact of $14-3-3 \zeta$ on key cellular activities and signaling pathways}

14-3-3 $\zeta$ status had a great impact on cell signaling pathways and the molecular properties of breast cancer cells.

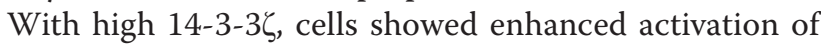
EGFR, HER2, MAPK, and AKT, and increased anchorage-dependent and independent growth. These activities were suppressed by downregulation of $14-3-3 \zeta$. Thus, $14-3-3 \zeta$ increases signaling through a variety of growth factor receptors and protein kinase pathways, stimulating a more robust and temporally prolonged activation of these pathways to promote survival and anti-apoptotic signaling, and enhance the endocrine resistance of breast cancer cells.

$14-3-3 \zeta$ is a member of a highly conserved family of 14-3-3 proteins, and it functions as a scaffold or platform that regulates the activity and stability of interacting proteins by binding to their phosphoserine and phosphothreonine motifs. It is noteworthy that $14-3-3 \zeta$ is the major form expressed in breast tumors and in ER-positive breast cancer cells, and it was the only 14-33 isoform to show high upregulation by tamoxifen. The broad effects of $14-3-3 \zeta$ might indeed be expected for a scaffold/adaptor protein that serves as a critical convergence factor in these signaling pathways, having known interactions with EGFR [13], HER2 [13], and PKC [11], as well as additional signaling components such as RAF-1 and $\beta$-catenin [12,14]. Our observations now add regulation of FOXM1 as another important aspect of $14-3-3 \zeta$ activity in breast cancer and endocrine resistance.

\section{4-3-3 $\zeta$ as a key marker of endocrine resistance and a} therapeutic target for endocrine therapy sensitization As $14-3-3 \zeta$ is overexpressed in breast cancers with a poor prognosis, and its elevated expression is associated with activation of growth factor and mitogenic signaling pathways and with endocrine resistance, our data imply that $14-3-3 \zeta$ should serve as a marker of resistance and a key therapeutic target for endocrine therapy sensitization and effective tumor suppression. Resistance to endocrine therapies is associated with enhanced signaling through growth factor receptor and downstream kinase pathways including MAPK and AKT [6,7,9,37-39]. Further, these signaling cascades result in the activation of additional kinases such as polo-like kinase 1 and the cyclin-CDKs, which are part of the 14$3-3 \zeta$ gene signature.

\section{Conclusions}

In summary, we find $14-3-3 \zeta$ to be a key marker for risk of failure on endocrine therapy and show that its elevated expression promoted resistance to endocrine therapies, whereas its downregulation slowed proliferation, enhanced apoptosis, and increased the sensitivity of breast cancer cells to endocrine treatment. From our studies and those of others [10,15,40-43], 14-3-3 $\zeta$ is emerging as a critical factor that has major impact on multiple forms of cancer therapy, endocrine therapies, and certain chemotherapies as well [44]. Our findings provide new mechanistic insights through definition of a gene signature and molecular phenotype associated with overexpression of $14-3-3 \zeta$ that contributes to endocrine resistance. Targeting $14-3-3 \zeta$ and the factors it regulates, such as FOXM1, should prove beneficial in delaying the development of endocrine resistance and in reversing resistance, and should allow more effective treatment of patients whose tumors overexpress $14-3-3 \zeta$ and are at high risk for disease recurrence.

\section{Abbreviations}

ER: estrogen receptor; FDR: false discovery rate; KD: knockdown; PCR: polymerase chain reaction; PI: propidium iodide; SAM: statistical analysis of microarrays; SERD: selective estrogen receptor downregulator; SERM: selective estrogen receptor modulator.

\section{Acknowledgements}

This research was supported by grants from The Breast Cancer Research Foundation (BSK) and the NIH (P50 AT006268, BSK), and a Postdoctoral 
Fellowship from the Department of Defense (W81XWH-09-1-0398, AB). We thank Dr. Jonna Frasor, University of Illinois at Chicago for valuable discussions and Dr. Nancy Weigel, Baylor College of Medicine, for providing lysine-coated adenovirus.

\section{Authors' contributions}

$A B$ conceived and designed the studies, carried out the experiments and data analysis, interpreted the data and wrote drafts of the manuscript. BC carried out some of the experimental studies and data analysis. BSK conceived and designed the studies, analyzed and interpreted the data, and wrote the manuscript. All authors read, made suggestions, and approved the final manuscript.

\section{Competing interests}

The authors declare that they have no competing interests.

Received: 13 December 2010 Revised: 10 February 2011

Accepted: 29 June 2011 Published: 29 June 2011

\section{References}

1. Frasor J, Stossi F, Danes JM, Komm B, Lyttle CR, Katzenellenbogen BS: Selective estrogen receptor modulators: discrimination of agonistic versus antagonistic activities by gene expression profiling in breast cancer cells. Cancer Res 2004, 64:1522-1533.

2. Frasor J, Danes JM, Komm B, Chang KC, Lyttle CR, Katzenellenbogen BS: Profiling of estrogen up- and down-regulated gene expression in human breast cancer cells: insights into gene networks and pathways underlying estrogenic control of proliferation and cell phenotype. Endocrinology 2003, 144:4562-4574.

3. Green KA, Carroll JS: Oestrogen-receptor-mediated transcription and the influence of co-factors and chromatin state. Nat Rev Cancer 2007, 7:713-722

4. Alexe G, Dalgin GS, Scanfeld D, Tamayo P, Mesirov JP, DeLisi C, Harris L, Barnard N, Martel M, Levine AJ, Ganesan S, Bhanot G: High expression of lymphocyte-associated genes in node-negative HER2+ breast cancers correlates with lower recurrence rates. Cancer Res 2007, 67:10669-10676.

5. Jordan VC: Chemoprevention of breast cancer with selective oestrogenreceptor modulators. Nat Rev Cancer 2007, 7:46-53.

6. Creighton CJ, Massarweh S, Huang S, Tsimelzon A, Hilsenbeck SG, Osborne CK, Shou J, Malorni L, Schiff R: Development of resistance to targeted therapies transforms the clinically associated molecular profile subtype of breast tumor xenografts. Cancer Res 2008, 68:7493-7501.

7. Schiff R, Massarweh S, Shou J, Osborne CK: Breast cancer endocrine resistance: how growth factor signaling and estrogen receptor coregulators modulate response. Clin Cancer Res 2003, 9:447S-454S.

8. Sengupta S, Schiff R, Katzenellenbogen BS: Post-transcriptional regulation of chemokine receptor CXCR4 by estrogen in HER2 overexpressing, estrogen receptor-positive breast cancer cells. Breast Cancer Res Treat 2009, 117:243-251.

9. Shou J, Massarweh S, Osborne CK, Wakeling AE, Ali S, Weiss H, Schiff R: Mechanisms of tamoxifen resistance: increased estrogen receptor-HER2/ neu cross-talk in ER/HER2-positive breast cancer. J Natl Cancer Inst 2004, 96:926-935.

10. Frasor J, Chang EC, Komm B, Lin CY, Vega VB, Liu ET, Miller LD, Smeds J, Bergh J, Katzenellenbogen BS: Gene expression preferentially regulated by tamoxifen in breast cancer cells and correlations with clinical outcome. Cancer Res 2006, 66:7334-7340.

11. Gannon-Murakami L, Murakami K: Selective association of protein kinase C with 14-3-3 zeta in neuronally differentiated PC12 Cells. Stimulatory and inhibitory effect of 14-3-3 zeta in vivo. J Biol Chem 2002, 277:23116-23122.

12. McPherson RA, Harding A, Roy S, Lane A, Hancock JF: Interactions of c-Raf1 with phosphatidylserine and 14-3-3. Oncogene 1999, 18:3862-3869.

13. Oksvold MP, Huitfeldt HS, Langdon WY: Identification of 14-3-3[zeta] as an EGF receptor interacting protein. FEBS Letters 2004, 569:207-210.

14. Tian Q, Feetham MC, Tao WA, He XC, Li L, Aebersold R, Hood L: Proteomic analysis identifies that 14-3-3zeta interacts with beta-catenin and facilitates its activation by Akt. Proc Natl Acad Sci USA 2004, 101:15370-15375.

15. Tzivion G, Gupta VS, Kaplun L, Balan V: 14-3-3 proteins as potential oncogenes. Semin Cancer Biol 2006, 16:203-213.
16. Sorlie T, Tibshirani R, Parker J, Hastie T, Marron JS, Nobel A, Deng S, Johnsen H, Pesich R, Geisler S, Demeter J, Perou CM, Lønning PE, Brown PO, Børresen-Dale AL, Botstein D: Repeated observation of breast tumor subtypes in independent gene expression data sets. Proc Natl Acad Sci USA 2003, 100:8418-8423.

17. van 't Veer $L J$, Dai $H$, van de Vijver MJ, He YD, Hart AA, Mao M, Peterse $H L$, van der Kooy K, Marton MJ, Witteveen AT, Schreiber GJ, Kerkhoven RM, Roberts C, Linsley PS, Bernards R, Friend SH: Gene expression profiling predicts clinical outcome of breast cancer. Nature 2002, 415:530-536.

18. Wang Y, Klijn JG, Zhang Y, Sieuwerts AM, Look MP, Yang F, Talantov D, Timmermans M, Meijer-van Gelder ME, Yu J, Jatkoe T, Berns EM, Atkins D, Foekens JA: Gene-expression profiles to predict distant metastasis of lymph-node-negative primary breast cancer. Lancet 2005, 365:671-679.

19. Tusher VG, Tibshirani R, Chu G: Significance analysis of microarrays applied to the ionizing radiation response. Proc Natl Acad Sci USA 2001, 98:5116-5121.

20. Tibshirani R, Hastie T, Narasimhan B, Chu G: Diagnosis of multiple cancer types by shrunken centroids of gene expression. Proc Natl Acad Sci USA 2002, 99:6567-6572.

21. Herman ME, Katzenellenbogen BS: Response-specific antiestrogen resistance in a newly characterized MCF-7 human breast cancer cell line resulting from long-term exposure to trans-hydroxytamoxifen. J Steroid Biochem Mol Biol 1996, 59:121-134.

22. Allgood VE, Zhang Y, O'Malley BW, Weigel NL: Analysis of chicken progesterone receptor function and phosphorylation using an adenovirus-mediated procedure for high-efficiency DNA transfer. Biochemistry 1997, 36:224-232.

23. Livak KJ, Schmittgen TD: Analysis of relative gene expression data using real-time quantitative PCR and the 2(-Delta Delta C(T)) Method. Methods 2001, 25:402-408.

24. Riccardi C, Nicoletti I: Analysis of apoptosis by propidium iodide staining and flow cytometry. Nature Protocols 2006, 1:1458-1461.

25. Huang da W, Sherman BT, Lempicki RA: Systematic and integrative analysis of large gene lists using DAVID bioinformatics resources. Nature Protocols 2009, 4:44-57.

26. Wang IC, Chen YJ, Hughes D, Petrovic V, Major ML, Park HJ, Tan Y, Ackerson T, Costa RH: Forkhead box M1 regulates the transcriptional network of genes essential for mitotic progression and genes encoding the SCF (Skp2-Cks1) ubiquitin ligase. Mol Cell Biol 2005, 25:10875-10894.

27. Sørlie T, Perou CM, Tibshirani R, Aas T, Geisler S, Johnsen H, Hastie T, Eisen MB, van de Rijn M, Jeffrey SS, Thorsen T, Quist H, Matese JC, Brown PO, Botstein D, Eystein Lønning P, Børresen-Dale AL: Gene expression patterns of breast carcinomas distinguish tumor subclasses with clinical implications. Proc Natl Acad Sci USA 2001, 98:10869-10874.

28. Matsukura S, Jones PA, Takai D: Establishment of conditional vectors for hairpin siRNA knockdowns. Nucleic Acids Res 2003, 31:e77.

29. Laoukili J, Kooistra MR, Bras A, Kauw J, Kerkhoven RM, Morrison A, Clevers $\mathrm{H}$, Medema $\mathrm{RH}$ : FoxM1 is required for execution of the mitotic programme and chromosome stability. Nat Cell Biol 2005, 7:126-136.

30. Costa RH: FoxM1 dances with mitosis. Nat Cell Biol 2005, 7:108-110.

31. Ando K, Ozaki T, Yamamoto H, Furuya K, Hosoda M, Hayashi S, Fukuzawa M, Nakagawara A: Polo-like kinase 1 (Plk1) inhibits p53 function by physical interaction and phosphorylation. J Biol Chem 2004, 279:25549-25561.

32. Tanaka K, Iwamoto S, Gon G, Nohara T, Iwamoto M, Tanigawa N: Expression of survivin and its relationship to loss of apoptosis in breast carcinomas. Clin Cancer Res 2000, 6:127-134.

33. Wang F, Dai J, Daum JR, Niedzialkowska E, Banerjee B, Stukenberg PT, Gorbsky GJ, Higgins JM: Histone H3 Thr-3 phosphorylation by Haspin positions Aurora B at centromeres in mitosis. Science 2010, 330:231-235.

34. Kelly AE, Ghenoiu C, Xue JZ, Zierhut C, Kimura H, Funabiki H: Survivin reads phosphorylated histone $\mathrm{H} 3$ threonine 3 to activate the mitotic kinase Aurora B. Science 2010, 330:235-239.

35. Yamagishi $Y$, Honda $T$, Tanno $Y$, Watanabe $Y$ : Two histone marks establish the inner centromere and chromosome bi-orientation. Science 2010, 330:239-243.

36. Bergamaschi A, Kim YH, Wang P, Sorlie T, Hernandez-Boussard T, Lonning PE, Tibshirani R, Borresen-Dale AL, Pollack JR: Distinct patterns of DNA copy number alteration are associated with different clinicopathological features and gene-expression subtypes of breast cancer. Genes Chromosomes Cancer 2006, 45:1033-1040. 
37. Arpino G, Wiechmann L, Osborne CK, Schiff R: Crosstalk between the estrogen receptor and the HER tyrosine kinase receptor family: molecular mechanism and clinical implications for endocrine therapy resistance. Endocr Rev 2008, 29:217-233.

38. Iorns E, Turner NC, Elliott R, Syed N, Garrone O, Gasco M, Tutt AN, Crook T, Lord CJ, Ashworth A: Identification of CDK10 as an important determinant of resistance to endocrine therapy for breast cancer. Cancer Cell 2008, 13:91-104.

39. Massarweh S, Osborne CK, Creighton CJ, Qin L, Tsimelzon A, Huang S, Weiss $H$, Rimawi M, Schiff R: Tamoxifen resistance in breast tumors is driven by growth factor receptor signaling with repression of classic estrogen receptor genomic function. Cancer Res 2008, 68:826-833.

40. Carr JR, Park HJ, Wang Z, Kiefer MM, Raychaudhuri P: FoxM1 mediates resistance to herceptin and paclitaxel. Cancer Res 2010, 70:5054-5063.

41. Danes CG, Wyszomierski SL, Lu J, Neal CL, Yang W, Yu D: 14-3-3 zeta down-regulates p53 in mammary epithelial cells and confers luminal filling. Cancer Res 2008, 68:1760-1767.

42. Lu J, Guo H, Treekitkarnmongkol W, Li P, Zhang J, Shi B, Ling C, Zhou X, Chen T, Chiao PJ, Feng X, Seewaldt VL, Muller WJ, Sahin A, Hung MC, Yu D: 14-3-3zeta Cooperates with ErbB2 to promote ductal carcinoma in situ progression to invasive breast cancer by inducing epithelialmesenchymal transition. Cancer Cell 2009, 16:195-207.

43. Neal CL, Yao J, Yang W, Zhou X, Nguyen NT, Lu J, Danes CG, Guo H, Lan KH, Ensor J, Hittelman W, Hung MC, Yu D: 14-3-3\{zeta\} Overexpression defines high risk for breast cancer recurrence and promotes cancer cell survival. Cancer Res 2009, 69:3425-3432.

44. Li Y, Zou L, Li Q, Haibe-Kains B, Tian R, Li Y, Desmedt C, Sotiriou C, Szallasi Z, Iglehart JD, Richardson AL, Wang ZC: Amplification of LAPTM4B and YWHAZ contributes to chemotherapy resistance and recurrence of breast cancer. Nat Med 2010, 16:214-218.

doi:10.1186/bcr2913

Cite this article as: Bergamaschi et al:: Reversal of endocrine resistance in breast cancer: interrelationships among 14-3-3ל, FOXM1, and a gene signature associated with mitosis. Breast Cancer Research 2011 13:R70.

\section{Submit your next manuscript to BioMed Central and take full advantage of:}

- Convenient online submission

- Thorough peer review

- No space constraints or color figure charges

- Immediate publication on acceptance

- Inclusion in PubMed, CAS, Scopus and Google Scholar

- Research which is freely available for redistribution

Submit your manuscript at www.biomedcentral.com/submit
Biomed Central 